\title{
Sementes crioulas: o estado da arte no Rio Grande do Sul
}

\author{
Andréia Becker Pelwing ${ }^{1}$ \\ Lúcia Brandão Frank ${ }^{2}$ \\ Ingrid I. Bergman de Barros ${ }^{3}$
}

Resumo: O presente estudo analisou o estado da arte das sementes tradicionais, crioulas ou landraces no estado do Rio Grande do Sul. Através de uma amostragem não probabilística, foi realizado um estudo etnográfico em 13 propriedades de oito municípios pertencentes às regiões da Grande Porto Alegre, Serra, Planalto Médio, Depressão Central e Serra do Sudeste. A pesquisa diagnosticou uma grande diversidade de plantas cultivadas de origem remota, mantidas nas propriedades dos agricultores tradicionais através de bancos de sementes. Ao todo, foram identificadas 39 espécies de plantas, distribuídas em 12 famílias botânicas, totalizando 258 apontamentos de plantas cultivadas crioulas no total dos entrevistados. A preferência da utilização de sementes crioulas, de acordo com relatos dos agricultores entrevistados, foi atribuída principalmente a características como a adaptabilidade, valorização dos costumes, o sabor e qualidade das variedades tradicionais, além do baixo custo de produção. Em relação às dificuldades de sua manutenção, as mais freqüentes foram o desinteresse das novas gerações e a dificuldade em trocar e obter sementes. Foram,

1 Mestre em Fitotecnia pela UFRGS. Professora do Centro Federal de Educação Tecnológica de São Vicente do Sul (CEFETSVS- UNED - Júlio de Castilhos RS).

2 Doutora em Zootecnia pela UFRGS. Professor Adjunto do Departamento de Plantas Forrageiras e Agrometereologia -Faculdade de Agronomia da UFRGS.

3 Doutora. Em Genética e Melhoramento de Plantas pela Universidade de São Paulo (USP). Professor Titular do Departamento de Horticultura e Silvicultura -

Faculdade de Agronomia da UFRGS. 
ainda, diagnosticadas estratégias de manutenção de variedades tradicionais desenvolvidas nas diferentes regiões como alternativas à conservação.

Palavras-chave: sementes crioulas, agrobiodiversidade, agricultura familiar, sustentabilidade.

\section{Classificação JEL: Q20}

Abstract: This study investigated the state of the art of traditional, or landrace seeds in the State of Rio Grande do Sul. An ethnographic study was carried out by means of a non-statistical seed sampling in 13 farms from eight municipalities lying in the regions of the Greater Porto Alegre, Serra, Planalto Médio, Depressão Central and Serra do Sudeste. A broad diversity of ancient plants was observed. These species survive in the farms with the help of a seed bank. All in all, 39 plant species were characterized, distributed in 12 families, totaling 258 instances of landrace seeds grown in the farms visited. According to the farmers, the preference for landrace seeds is due chiefly to seed adaptability, better flavor and quality of the produce grown therefrom, valuablezation of customs and lower production costs. As regards seed upkeep, the most common difficulties mentioned were the lack of interest by the younger generations, and the obstacles in swapping and obtaining seeds. Alternatives to the upkeep of traditional seeds developed in different zones were also discussed as choices to plant conservation.

Key words: landrace seeds; agrobiodiversity; family agriculture; sustainability.

\section{JEL Classification: Q20}

\section{Introdução}

Como observadores da natureza, os caçadores-coletores foram provavelmente também bons contempladores das relações entre plantas e animais muito antes de fazerem uso da agricultura. De acordo com Evans (1996), embora os povos aborígenes na Austrália não tivessem 
ainda domesticado plantas ou praticado cultivos, eles reconheciam a relação entre sementes e plantas e, quando encontravam painço selvagem, eles algumas vezes dispersavam sementes para garantir a colheita do próximo ano. Da mesma forma, quando coletavam inhames (Dioscorea $s p$.) eles normalmente devolviam a parte superior do ramo ao orifício do qual eles o haviam extraído. Isso provavelmente os redimia do roubo com o espírito do inhame, mas também servia para dar origem a uma nova geração de inhames.

Alguns estudiosos como Heiser (1977) e Louwaars (1994) discutem que o cultivo das plantas pelo homem começou, provavelmente, pela propagação vegetativa, argumentando que essa forma de cultivo é muito mais simples que a semeadura. No entanto, o fato do plantio a partir das sementes ter sido responsável pelas mais profundas mudanças na vida do homem é defendido por muitos pesquisadores (Heiser, 1977; Evans,1996; Ornellas, 2003; Louwaars, 1994).

A relação entre a figura feminina e o desenvolvimento da agricultura pelas civilizações primitivas é um aspecto que tem sido abordado com bastante ênfase na literatura. De acordo com Eisler (1995) apud Dominguez et al. (2000), é mais provável que tenham sido as mulheres que primeiro enterraram sementes no solo e iniciaram a doma dos animais jovens, alimentando-os e tomando conta deles, como faziam com seus filhos. As mulheres começaram a perceber a capacidade de germinação e, a partir deste fenômeno, a possibilidade de "concentrar” a produção dos alimentos. Além dessa questão, fatos históricos, embora fragmentados e não de todo compreendidos, levam a crer que a agricultura, uma vez estabelecida como modo de vida de civilizações antigas, era tida como objeto de importância fundamental e ligada, dessa forma, a todos os campos de relações da vida de certas comunidades, chegando a fundirse com acontecimentos religiosos e mágicos.

Além das múltiplas interpretações atuais que tentam elucidar como a agricultura se desenvolvia nas várias antigas civilizações cultivadoras, também são muitas as dúvidas a respeito do período em que as atividades agrícolas passaram a fazer parte da economia humana e também onde ela exatamente se deu. Segundo Raven et al. (1996), a domesticação de plantas e animais teve início por volta de 11.000 anos atrás (período Neolítico), na região conhecida como "Crescente Fértil" 
do Mediterrâneo oriental, em terras que se estendem através de partes do que hoje constitui o Líbano, Síria, Turquia, Irã e Iraque. Para Evans (1996) naturalmente os pesquisadores europeus, imersos na glória de que foi Grécia e na grandeza de que foi Roma, focaram os antecedentes das civilizações agricultoras globais no seu 'quintal', fundamentados basicamente na riqueza paleobotânica de tais regiões, devido, em grande parte, às condições favoráveis à preservação lá encontradas, em função de seu clima árido.

Alguns pesquisadores, como De Candolle (1855) e Darwin (1868), já reconheciam que as plantas cultivadas de hoje haviam sido domesticadas em associação com os centros de origem das diferentes civilizações no mundo todo, mas foi Nicolai I. Vavilov (1926-1951) que propôs a existência de centros de origem para a maior parte das plantas cultivadas. A teoria se baseou em evidências de mais de 300.000 coletas realizadas por ele e outros pesquisadores, revelando um número relativamente pequeno de regiões onde se iniciou a domesticação das plantas, nos mais diversos ambientes e culturas do planeta, recebendo a denominação de “oito centros de origem da agricultura” (Querol,1993; Mooney,1987; Evans,1996; Louwaars,1994).

De acordo com Mazoyer \& Roudart (1998), desde o início do desenvolvimento da agricultura, a base alimentar das diferentes civilizações foi sendo modificada de acordo com o tipo de agricultura lá desenvolvido, que variava conforme a evolução das condições ecológicas e características culturais dos grupamentos humanos nas diferentes regiões do mundo. Desde o advento da agricultura, há aproximadamente 10.000 anos, as maiores mudanças nos hábitos alimentares da humanidade se deram a partir do "descobrimento" das Américas, há aproximadamente 500 anos. Após o marco do descobrimento, houve não só a intensificação do intercâmbio de espécies cultivadas como também a modificação radical da alimentação da maioria da humanidade, além do crescente desenvolvimento de cultivos comerciais nos trópicos, criando uma nova ordem econômica no mundo (Pessanha, 1995). No Brasil, esta relação produtivista gerou ciclos de cultivos comerciais, como o da cana-deaçúcar, de mão-de-obra escrava.

No início do século XX, em decorrência de paradigmas vigentes principalmente a partir da Revolução Industrial, a introdução e 
substituição de espécies e variedades torna-se mais veloz, produzindo enormes flutuações na paisagem agrícola, produtos e formas de consumo (Bermejo \& Leon, 1992). A partir dos anos 50, a chamada Revolução Verde, baseada em práticas mecânicas, uso de variedades de alto rendimento e de insumos químicos foi a resposta em relação às demandas internacionais que a produção de alimentos passou a ter após a Segunda Guerra Mundial (Pinheiro et al., 2000). Sendo o modelo que trouxe um acréscimo real ao potencial produtivo, as vantagens e desvantagens desse paradigma são motivo de discussões: para uns significou a solução dos problemas no abastecimento de alimentos; para outros, o início do fim, a destruição da natureza, ficando as sementes no centro das controvérsias (Dominguez et al., 2000).Embora a Revolução Verde tenha sido responsável pela perda de grande parte da diversidade e variabilidade das plantas cultivadas, em função da transformação de agroecossistemas em monocultivos de variedades de estreita base genética, existe ainda hoje um número considerável de propriedades rurais que mantêm plantas cultivadas que só foram melhoradas pelas mãos de agricultores e agricultoras, denominadas variedades tradicionais, antigas, caseiras, landraces (raças da terra) ou crioulas. Estas variedades, que detêm a maior variabilidade dentre as plantas cultivadas, são mantidas em grande parte através de bancos de sementes de agricultores de todo o mundo e, principalmente, nos países em desenvolvimento.

Nos últimos anos, tem-se dado atenção especial às comunidades agrícolas tradicionais não só como mantenedoras da diversidade biológica natural, em função de suas práticas agrícolas de baixo impacto, mas também como guardiãs da variabilidade e biodiversidade das plantas cultivadas e do conhecimento associado a toda essa riqueza. De acordo com Bermejo \& León (1992), as variedades locais são aquelas que possuem a maior parte da variabilidade vegetal dentre as plantas cultivadas e, assim como tantos outros recursos naturais, o que se perde não se recupera mais.

Segundo Brush (2000), o crescente valor atribuído aos cultivos tradicionais tem resultado na criação de programas de conservação de tais recursos. No Brasil, trabalhos de referência são relatados na literatura como tendo início nas décadas de 1970 e 1980 (Gaifami \& Cordeiro, 1994; Almeida \& Cordeiro, 2002). 
O Rio Grande do Sul é caracterizado por uma variada gama de espaços agrícolas e riqueza étnica, possuindo grande potencial no que se refere à manutenção de recursos genéticos através de bancos de sementes e mudas (Verdum et al. 2004). Dutra (2005) associa a manutenção das sementes tradicionais no estado à escala do sistema de produção gaúcho que, baseado em grande parte na forma de produção familiar, se constitui de propriedades com um tamanho de 20 hectares em média, muito menor que a média das propriedades da região Centro-Oeste, por exemplo, que realizam cultivos em maior escala. Esta particularidade, segundo Dutra (2005), possibilita ainda certa dedicação à produção de sementes tradicionais por alguns agricultores gaúchos. Schneider \& Waquil (2001), demonstram através de uma caracterização socioeconômica dos municípios a heterogeneidade e as potencialidades do estado, justamente por suas características de renda, produtividade, infra-estrutura e formas de exploração que em grande parte ainda asseguram qualidade de vida e conservação dos recursos naturais, principalmente devido à forma como os recursos vêm sendo explorados, argumentando que tais práticas nem sempre são diretamente proporcionais ao tamanho da área explorada e ao acesso a tecnologias estabelecidas pelo mercado.

A diversidade socioambiental dos espaços agrícolas sul-riograndenses foi a maior motivadora do presente estudo, que objetivou reconhecer a importância da conservação das sementes antigas ou crioulas de plantas cultivadas na ótica dos agricultores que ainda as mantêm, buscando evidências da existência da diversidade de sementes de diferentes espécies e variedades tradicionais nas propriedades amostradas. Além disso, prestou-se a identificar as preferências quanto ao uso e as dificuldades por eles encontradas na manutenção das sementes tradicionais, bem como as estratégias desenvolvidas pelos "agricultores sementeiros" para a conservação de tais recursos.

\section{Material e Métodos}

O trabalho de diagnóstico a respeito da existência de sementes tradicionais de espécies vegetais cultivadas foi realizado entre maio de 2004 a dezembro de 2005, através da prospecção de instituições 
que desenvolvem trabalhos de pesquisa, incentivo à manutenção e promoção do cultivo dessas sementes, seguido da localização dos informantes-chave e levantamento das espécies e variedades tradicionais nas propriedades amostradas.

\subsection{Localização das Instituições}

O levantamento foi realizado inicialmente através do contato com organizações formais e não formais, movimentos sociais, instituições públicas e privadas, por intermédio de pesquisa bibliográfica, internet, contato telefônico e participação em encontros de promoção do uso de variedades tradicionais.

A partir de então, houve uma sistematização das atribuições das diferentes instituições, possibilitando identificar aquelas envolvidas com trabalhos de pesquisa, manutenção, resgate, promoção do uso, organização de eventos, beneficiamento ou qualquer trabalho ligado diretamente a comunidades de agricultores que ainda utilizam sementes tradicionais.

A sistematização das informações desencadeou o exercício de compreensão da ação institucional e articulação inter-institucional, permitindo a identificação dos atores e processos que fazem parte desta rede de relações. A partir de tal compreensão, representantes das instituições envolvidas com o trabalho de manutenção e promoção do uso de sementes tradicionais foram entrevistados, contribuindo posteriormente na localização de agricultores de diferentes regiões do estado do Rio Grande do Sul que utilizam sementes crioulas.

\subsection{Localização dos informantes-chave e levantamento amostral}

A forma de amostragem dos agricultores-sementeiros do estado foi não probabilística, uma vez que o universo amostral não era conhecido. No entanto, procurou-se realizar uma amostragem diversificada, dando especial atenção à diversidade das características culturais, organizacionais e ambientais. Em cada grupo ou região estudada foram utilizados métodos etnográficos como ferramentas de pesquisa. Para fins de registro foram utilizados máquina fotográfica, diário de campo, 
ficha de entrevista semi-estruturada e gravador de áudio. Realizaramse coletas da planta como um todo (em exsicatas) e de sementes (para identificação de espécies de leguminosas, por exemplo).

A partir da localização de um informante-chave indicado por uma instituição conhecedora da realidade local específica, o método empregado para localizar outros informantes foi o método "bola de neve" (Bernard, 1988).

Com cada informante-chave (agricultor ou agricultora) foi realizada uma entrevista semi-estruturada, objetivando a coleta de informações a respeito do conhecimento, obtenção, importância, dificuldades e estratégias locais para manutenção das variedades tradicionais.A partir de uma conversa informal seguia-se a entrevista semi-estruturada, caracterizando-se como a atividade de coleta de dados mais relevante. Outros procedimentos complementares na coleta de dados se constituíram de caminhadas na horta da propriedade, quando esta ainda estava estruturada em função da época - e, no presente ano, em função de intempéries climáticas, que através da estiagem impactaram os agroecossistemas das regiões amostradas - e visitação ao local de armazenagem das sementes.

O tempo de permanência em cada região e número de agricultores entrevistados em cada município foi proporcional à relevância das estratégias locais desenvolvidas para a pesquisa em questão, do número de propriedades indicadas como envolvidas na manutenção de variedades tradicionais e da disponibilidade de tempo como um todo.

\section{Resultados}

\subsection{Instituições que desenvolvem trabalhos de pesquisa ou promoção de sementes crioulas}

Como resultado do contato com instituições envolvidas em trabalhos com sementes crioulas no estado, foi possível sistematizar as informações sobre as atribuições de cada uma delas (Tabela 1). Além de trabalhos de pesquisa com variedades tradicionais realizados por algumas instituições públicas, muitas foram as estratégias, desenvolvidas por diferentes órgãos e movimentos sociais, identificadas para viabilizar a 
manutenção e promoção do uso de sementes crioulas em comunidades agrícolas. No entanto, foram observadas dificuldades por parte de movimentos e ONGs envolvidas em tais trabalhos, sendo a carência de apoio governamental para a viabilização de trabalhos de multiplicação e promoção do uso das sementes crioulas um apontamento unânime.

Tabela 1. Instituições contatadas para localização dos agricultoressementeiros em diferentes regiões do estado do Rio Grande do Sul.

\begin{tabular}{|c|c|c|}
\hline Natureza da Instituição & Sigla* & Trabalho desenvolvido \\
\hline Associação & UNAIC & $\begin{array}{l}\text { Manutenção, resgate, promoção de eventos, } \\
\text { beneficiamento de sementes. }\end{array}$ \\
\hline Instituição Mista & $\begin{array}{l}\text { EMATER/ } \\
\text { ASCAR }\end{array}$ & Manutenção, resgate, promoção de eventos. \\
\hline Instituição Pública & EMBRAPA & $\begin{array}{l}\text { Resgate, multiplicação, caracterização } \\
\text { morfológica e molecular de acessos. }\end{array}$ \\
\hline Instituição Pública & FEPAGRO & $\begin{array}{l}\text { Resgate, avaliação, criação de coleções de } \\
\text { sementes. }\end{array}$ \\
\hline Movimento Social & MPA & $\begin{array}{l}\text { Manutenção, resgate, promoção de eventos e } \\
\text { feiras, cartilha de sementes. }\end{array}$ \\
\hline Movimento Social & MST & $\begin{array}{l}\text { Manutenção, resgate, promoção de eventos e } \\
\text { feiras, banco de sementes em escolas. }\end{array}$ \\
\hline ONG & CAPA & $\begin{array}{c}\text { Manutenção, resgate, promoção de eventos e } \\
\text { feiras troca-troca. }\end{array}$ \\
\hline ONG & CAE & $\begin{array}{l}\text { Manutenção, resgate, promoção de eventos e } \\
\text { feiras troca-troca, casa de variedades crioulas. }\end{array}$ \\
\hline ONG & IACOREQ & $\begin{array}{c}\text { Identificação da existência de variedades de } \\
\text { sementes crioulas. }\end{array}$ \\
\hline ONG & CETAP & $\begin{array}{l}\text { Manutenção, resgate, promoção de eventos e } \\
\text { feiras troca-troca. }\end{array}$ \\
\hline Universidade Federal & UFRGS & $\begin{array}{l}\text { Caracterização da variabilidade genotípica, } \\
\text { citogenética e marcadores moleculares. }\end{array}$ \\
\hline Universidade Federal & UFPel & $\begin{array}{l}\text { Estudos, discussões e produção de material } \\
\text { bibliográfico sobre o sistema informal de } \\
\text { sementes. }\end{array}$ \\
\hline
\end{tabular}

UNAIC (União das Associações do Interior de Canguçu); EMATER (Associação Riograndense de Empreendimentos de Assistência Técnica e Extensão Rural)/ASCAR (Associação Sulina de 
Crédito e Assistência Rural); EMBRAPA (Empresa Brasileira de Pesquisa Agropecuária); FEPAGRO (Fundação Estadual de Pesquisa Agropecuária); MPA (Movimento dos Pequenos Agricultores); MST (Movimento dos Sem Terra); CAPA (Centro de Apoio ao Pequeno Agricultor); CAE (Centro Agrícola Ecológico); IACOREQ (Instituto de Assistência a Comunidades Remanescentes de Quilombos); CETAP (Centro de Técnicas Alternativas Populares); UFRGS (Universidade Federal do Rio Grande do Sul); UFPel (Universidade Federal de Pelotas).

\subsection{Amostragem de agricultores que ainda utilizam sementes próprias}

Foram amostradas 13 propriedades de agricultores que utilizam sementes próprias em 8 municípios do estado (Figura 1).

A amostragem contemplou municípios pertencentes a cinco das nove regiões do estado apontadas por Verdum et al. (2004), a saber: Região Litorânea (Palmares do Sul, com duas propriedades amostradas); Serra do Nordeste (Ipê e Antônio Prado, com duas e uma propriedades amostradas, respectivamente); Depressão Central (Bom Retiro do Sul e Arroio do Meio, com uma e duas propriedades amostradas, respectivamente); Planalto Médio (Santo Antônio do Palma, com três propriedades amostradas) e Serra do Sudeste (Canguçu, com uma propriedade amostrada).
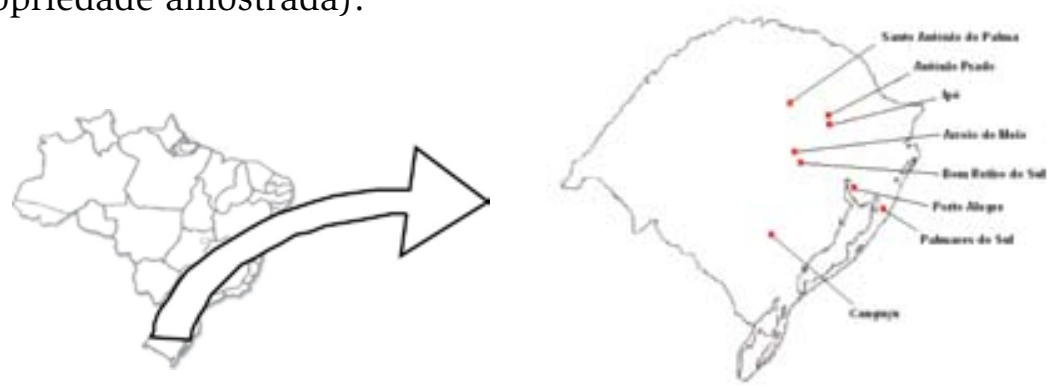

Figura 1: Localização dos municípios onde foram contatados os informantes-chave.

\subsection{Relações sócio-econômicas das propriedades}

Todos os entrevistados relataram ter sempre trabalhado como agricultores. Isto é, são pessoas de tradição agrícola e, na maioria dos casos, aprenderam com os pais o que estes haviam aprendido com os seus em relação às práticas desenvolvidas no meio rural. Em alguns casos, como o exemplo do agricultor Neuclides Marcon, de 
Ipê, houve a conciliação de outras atividades durante alguns anos de sua vida com as do campo, já que não possuía terra própria, apesar da tradição familiar agrícola. Atualmente possui propriedade em seu nome, adquirida há 10 anos, e a partir de então vem dedicandose exclusivamente à agricultura. Outra entrevistada, a agricultora Merecilda Matos de Oliveira, moradora da comunidade do Limoeiro, de Palmares do Sul, passou a maior parte de sua vida trabalhando em fazendas da região. Reside atualmente em terra própria - apesar de ainda não possuir registro oficial ${ }^{4}$ - que recebeu de herança de seu sogro há mais de 10 anos.

Todas as agricultoras e agricultores das propriedades amostradas revelaram possuir tradição agrícola e, na maior parte das vezes, características culturais bem evidenciadas. Na maior parte das propriedades os agricultores continuam produzindo no mesmo local ou em terras próximas de onde seus ascendentes o faziam, somando às práticas agrícolas tradicionais, o conhecimento a respeito do solo, clima e interações ecológicas locais.

Os dados amostrados revelaram a troca de sementes entre os parentes (69\% das propriedades) e a troca entre os vizinhos (61\% das propriedades) como as principais formas de intercâmbio; em segundo lugar, as feiras e festas, em sua maioria organizada por ONGs locais, se mostraram também como importantes formas de viabilização das trocas (38 \% das propriedades). Outros elementos de relevância para o intercâmbio de sementes, segundo os entrevistados, foram as casas de sementes ( $23 \%$ das propriedades) e, ainda, através da extensão rural $(15 \%)$.

Em 30\% das propriedades as variedades tradicionais são utilizadas somente para consumo próprio e na alimentação de animais. Em 70\% delas a utilização é tanto para consumo próprio e trato dos animais, quanto para a comercialização. Os agricultores que comercializam

4 Atualmente o Rio Grande do Sul conta com 27 comunidades negras rurais em que não se realizaram estudos de diagnóstico especializado; 42 comunidades rurais negras que foram caracterizadas como potencialmente remanescentes de quilombolas através de um 'Diagnóstico das Comunidades Negras Rurais Remanescentes de Quilombos' - dentre as quais encontra-se a comunidade do Limoeiro - e com seis comunidades apontadas como remanescentes de quilombos através de laudos antropológicos (Rubert, 2005). 
produtos oriundos de sementes próprias atribuem ao comércio de tais produtos $60 \%$ da renda mensal. O tamanho das propriedades amostradas foi em média de 20 ha, variando de 0,25 a 75 ha.

\subsection{Relações interpessoais, institucionais e formas de organização social}

O levantamento realizado nas propriedades de agricultores evidenciou algumas particularidades quanto à divisão do trabalho em relação ao manejo, beneficiamento e acondicionamento das sementes. Em quatro das 13 propriedades amostradas, o trabalho com as sementes foi considerado atividade masculina. Apenas em duas propriedades foi possível diagnosticar unicamente o trabalho feminino ligado ao manejo com as sementes. Na maior parte dos casos evidenciou-se a divisão de trabalho homem/ mulher, onde cada um desempenha um papel diferenciado em relação ao manejo das sementes. Em sete propriedades, enquanto os homens colhem, secam e se preocupam com as sementes de espécies que requerem um maior volume para a armazenagem, como acontece principalmente no caso do milho (Zea mays L.) e feijões (Phaseolus sp.), as mulheres se detêm no trabalho mais delicado, como a secagem de sementes de olerícolas como alface (Lactuca sativa L.), abóboras (Cucurbita sp.) e melão (Cucumis melo L.). Nestes casos, o volume de sementes manejadas e armazenadas para o plantio no ano seguinte é significativamente menor.

Em $69 \%$ das propriedades amostradas foi observada a organização dos agricultores e agricultoras em associações não formais, formais e mesmo em grupos formais constituídos da união entre diferentes associações. Decisões a respeito do manejo dos cultivos, divisão e cronograma de trabalho - época de plantio, oferta de produtos e discussões com instituições sobre demandas locais - são realizadas coletivamente. Grande parte dos agricultores (85\%) estabelece algum tipo de relação com ONGs, seguido de instituições de extensão rural (69\%) e, em menor número, com instituições de pesquisa (31\%).

Nas regiões estudadas foram identificadas iniciativas locais voltadas direta ou indiretamente à manutenção e resgate de sementes de variedades tradicionais. Estratégias como a organização do Jantar Ecológico institucionalizado pelo município de Santo Antônio do Palma, reuniu mais de mil pessoas nos anos de 2004 e 2005, é um exemplo de 
articulação local como forma de valorizar tradições, práticas e recursos locais. Além desta, outras iniciativas como a distribuição da produção para a merenda de escolas municipais, estaduais e federais (Canguçu, Santo Antônio do Palma); feiras troca-troca de sementes, organização de feiras ecológicas locais, regionais e estaduais (Canguçu, Ipê); casas regionais de variedades crioulas (CVC de Ipê), romarias da terra (em diferentes municípios a cada ano), unidades de beneficiamento de sementes (UBS de Canguçu), além de discussão sobre formas de implementação de bancos de dados sobre sementes (em todo o estado), para facilitar a disseminação de informações e localização das sementes entre agricultores de diferentes regiões, foram observadas.

\subsection{Coleta, beneficiamento e acondicionamento das sementes}

A amostragem permitiu identificar soluções simples e eficazes desenvolvidas pelos agricultores no beneficiamento e acondicionamento de sementes. Foi possível diagnosticar que as formas de manejo dependem da espécie em questão. De um modo geral, os agricultores utilizam o vento, sombra ou sol para a secagem de suas sementes. No caso de sementes de abóbora, melão e tomate, por exemplo, as sementes são dispostas em papel, peneira ou tela, para melhor aeração, por um período que varia de dois dias a uma semana, de acordo com o tratamento escolhido (sol ou sombra) e da espécie ou variedade em questão. Três agricultoras entrevistadas pertencentes a comunidades de Remanescentes de Quilombos, uma da comunidade do Limoeiro (Palmares do Sul) e duas de São Roque (Arroio do Meio), penduram suas sementes em sacos de pano ou tela, muitas vezes dispostos próximos ao fogão à lenha, para facilitar a secagem, evidenciando a existência de um método tradicional de secagem ainda mantido.

Em relação ao acondicionamento das sementes, soluções recentes mesclam-se com métodos antigos, ainda não de todo esquecidos. Em relação a espécies de leguminosas é válido destacar dois métodos de acondicionamento utilizados por agricultores de ascendência italiana há muitos anos e tidos por eles como eficazes na conservação das sementes. Um deles é o método ‘entre palha’ e o outro é o método ‘entre areia’. A primeira forma de acondicionamento consiste em deixar as 
sementes de feijão entre a sua "própria palha”, ou seja, ainda envoltas pela vagem, em um recipiente aberto (tonel). Nesse caso, não de um ano para outro, mas por um período de semanas a meses, em que o agricultor esteja priorizando outras atividades. Segundo o agricultor, o feijão permanece sadio e livre do ataque de insetos. $\mathrm{O}$ outro método é o acondicionamento dos feijões em recipiente de barro preenchido com areia. A técnica foi utilizada durante muitos anos pelo agricultor Manoel da Silva Velho e por outros parentes e vizinhos da localidade de Beco Mato Grande, em Palmares do Sul, para armazenagem de longa duração dos grãos, porém vem sendo substituída por outras nos últimos anos. Com o crescente número de embalagens disponíveis nas últimas décadas, a maior parte dos agricultores está gradualmente aderindo a embalagens plásticas (garrafas 'pet') e frascos de vidro para armazenagem das sementes. Também são utilizados sacos de papel, estes com menor freqüência. Dos treze entrevistados, 31 \% têm o cuidado com a luz (armazenagem no escuro - embalagens escuras ou cobertas); $15 \%$ disseram utilizar temperaturas baixas no acondicionamento de certas sementes (geladeira); e 15\% deles têm o cuidado de "retirar o ar" do interior dos vidros assim que acondicionam as sementes, queimando um pedaço de algodão embebido em líquido combustível (álcool) no interior do frasco antes de fechá-lo, com a finalidade de evitar o desenvolvimento de insetos.

\subsection{Diversidade de sementes crioulas de plantas cultivadas}

O levantamento realizado diagnosticou uma grande diversidade de sementes de plantas cultivadas tidas pelos agricultores das propriedades amostradas como antigas ou 'crioulas'. Foram listadas 258 plantas reconhecidas pelos 13 agricultores e agricultoras como tradicionais, com uma média de 20 plantas por propriedade, distribuídas em 12 famílias botânicas (Figura 2). Desse total, 157 apontamentos foram a respeito de sementes de plantas cultivadas crioulas de origem remota, constituindo $65 \%$ do total das menções por propriedade. Ao todo, foram identificadas 39 espécies botânicas, apresentando um grande número de variedades locais para a maioria delas (Tabela 2).

A maior parte dos agricultores possui sementes antigas ou 
'crioulas' de leguminosas (Faboideae). Dentre as 'variedades antigas' de feijões mencionados, além do feijão comum (Phaseolus vulgaris L.), apresentando grande variação de cores, morfologia e usos, foram identificadas variedades das espécies $P$. lunatus $L$. e $P$. coccineus $L$., além do gênero Vigna. De acordo com o agricultor Vilmar Menegat, detentor da variedade de feijão conhecido localmente como 'Feijão Ornamental' ou 'Lab-Lab', espécie identificada como $P$. coccineus $L$., a mesma possui características peculiares, que diferem do feijão comum (P. vulgaris L.), como a baixa produção de grãos em relação à parte vegetativa, sendo utilizado como forragem, além de se prestar à ornamentação de jardins, devido à coloração vermelha de suas flores. O feijão 'Olho-de-Cabra' ( $P$. lunatus L.) é mantido pelos agricultores principalmente devido às várias formas de utilização, como alimentação humana e artesanato (em função de sua coloração), além de ter uso na alimentação animal. Outra variedade de feijão, pertencente à espécie Vigna unguiculata L., denominado 'Branquinho' ou 'Sopinha' pela comunidade de Remanescentes de Quilombos Limoeiro, é mantida por esta e outras comunidades rurais negras do estado, como a comunidade de RQ de Casca, localizada no município de Mostardas (Pinheiro, 2005). Além dos feijões, foram identificadas variedades tradicionais de sementes de fava (Vicia faba L.), amendoim (Arachys hypogaea L.) e ervilha (Pisum sativum L.).

Os usos das variedades das diferentes famílias identificadas no levantamento vão desde a alimentação a usos bastante peculiares. Certas variedades são mantidas em função de alguma característica interessante ao agricultor no que se refere ao manejo do agroecossistema como, por exemplo, a variedade de girassol (Helianthus annuus L.) conhecida como 'Girassol Gigante', utilizada no consórcio com os demais cultivos das hortas, auxiliando no sombreamento de estratos vegetais mais baixos. O 'Trigo Morisco', Fagopyrum esculentum Gilib., é reconhecido pela família de agricultores de ascendência polonesa que mantém a variedade tradicional da espécie como sucedâneo dos cereais comuns na dieta de pessoas intolerantes ao glúten, deficiência conhecida como doença celíaca, informação que também pode ser encontrada em bibliografia. Na propriedade, a variedade é utilizada principalmente como recurso alimentar dos animais, adubação de cobertura de solo, além da produção de farinha para alimentação familiar. 
Figura 2. Número de variedades 'crioulas' mencionadas nas propriedades amostradas.

\section{Total de sementes mencionadas como "crioulas" nas propriedades, por familia botânica}

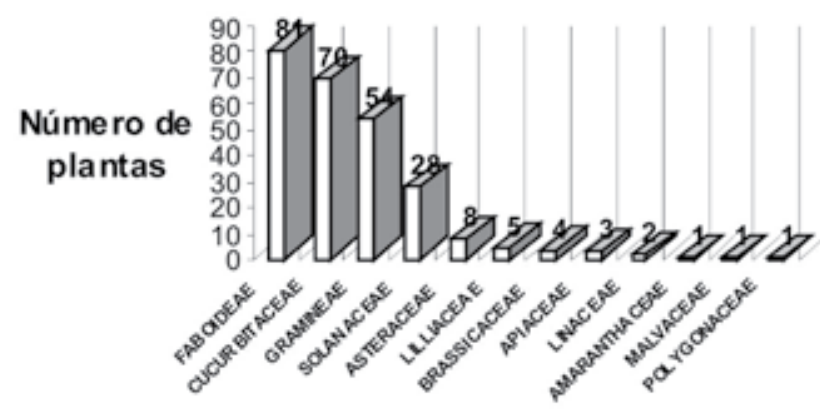

Familias

Tabela 2. Nomenclatura científica, taxonomia de folk e centros de origem das espécies identificadas no levantamento.

\section{$\begin{array}{lll}\text { Nomenclatura científica } & \text { Taxonomia de folk Centro de origem }\end{array}$}

\begin{tabular}{|c|c|c|}
\hline $\begin{array}{l}\text { FABACEAE: FABOIDEAE } \\
\text { Phaseolus vulgaris L. }\end{array}$ & $\begin{array}{l}\text { Feijão Nova Roma, } \\
\text { Amendoim, Macarrão, } \\
\text { Mamono. }\end{array}$ & $\begin{array}{l}\text { Sul do México e } \\
\text { AméricaCentral * }\end{array}$ \\
\hline Phaseolus lunatus L. & Feijão Olho de Cabra, Grande. & $\begin{array}{l}\text { Sul do } \\
\text { México e } \\
\text { América } \\
\text { Central* }\end{array}$ \\
\hline Phaeolus coccineus $\mathrm{L}$ & Feijão Ornamental, Lab-Lab. & $\begin{array}{l}\text { Sul do México } \\
\text { e América } \\
\text { Central* }\end{array}$ \\
\hline $\begin{array}{l}\text { Vina unguiculata (L). } \\
\text { Walp. }\end{array}$ & $\begin{array}{l}\text { Feijão Sopinha, Feijão } \\
\text { Branquinho. }\end{array}$ & Ìndia * \\
\hline$\overline{\text { Vigna sinensis (L). Savi } c f \text {. }}$ & $\begin{array}{l}\text { Feijão Miúdo Preto, Miúdo } \\
\text { Encarnado. }\end{array}$ & Índia; África Tropical** \\
\hline
\end{tabular}




\begin{tabular}{lll}
\hline Arachis hypogaea L. & $\begin{array}{l}\text { Amendoim, Amendoim } \\
\text { Graúdo. }\end{array}$ & Brasileiro - Paraguaio* $^{*}$ \\
\hline Pisum sativum L. & Ervilha, Ervilha Grande. & $\begin{array}{l}\text { Ásia Central, Abissínico, } \\
\text { Oriente Próximo }\end{array}$ \\
\hline Vicia faba L. & Fava, Faba. & Ásia Central, Abissínico*
\end{tabular}

\section{CUCURBITACEAE}

\begin{tabular}{|c|c|c|}
\hline Cucurbita pepo L. & $\begin{array}{l}\text { Abóbora Dez Mandamentos, } \\
\text { Moranga, Abobrinha. }\end{array}$ & América Central, *** \\
\hline $\begin{array}{l}\text { Cucurbita maxima } \\
\text { Duschesne. }\end{array}$ & Moranga. & América do Sul $*, * *$ \\
\hline $\begin{array}{l}\text { Cucurbita moschata } \\
\text { Duschesne. }\end{array}$ & $\begin{array}{l}\text { Abóbora de Bassai, Moranga } \\
\text { de Tortéi. }\end{array}$ & $\begin{array}{l}\text { Sul do México e América } \\
\text { Central } *, * *\end{array}$ \\
\hline $\begin{array}{l}\text { Citrullus lanatus (Thunb.) } \\
\text { Mansf. }\end{array}$ & $\begin{array}{l}\text { Melancia Amarela, Melancia } \\
\text { de Porco. }\end{array}$ & África ** \\
\hline Cucumis melo L. & $\begin{array}{l}\text { Melão Doce, Gaúcho, Melão } \\
\text { de Neve, Melão Neve. }\end{array}$ & $\begin{array}{l}\text { Oriente Próximo, Ásia } \\
\text { Central, África** }\end{array}$ \\
\hline Cucumis sativus L. & $\begin{array}{l}\text { Pepino de Salada, Pepino de } \\
\text { Conserva. }\end{array}$ & Índia, China * \\
\hline Momordica charantia L. & Melão de São-Caetano. & Índia * \\
\hline $\begin{array}{l}\text { Sicana odorifera (Vell.) } \\
\text { Naudin }\end{array}$ & Maracujá, Maracujá Melão. & $\begin{array}{l}\text { Sul do México e América } \\
\text { Central * }\end{array}$ \\
\hline $\begin{array}{l}\text { Lagenaria siceraria (Mol.) } \\
\text { Standl. }\end{array}$ & $\begin{array}{l}\text { Caxi, Porongo de Chuchu, } \\
\text { Porongo de Metro. }\end{array}$ & Indiano e Ásia Central * \\
\hline
\end{tabular}

Luffa cylindrica Roem. Bucha, Esfregão. Chinês *

\section{GRAMINEAE}

\begin{tabular}{lll}
\hline Zea mays L. & $\begin{array}{l}\text { Milho Oito Carreiras, Milho } \\
\text { Palha Roxa, Pururuca... }\end{array}$ & $\begin{array}{l}\text { Sul do México e Ásia } \\
\text { Central * }\end{array}$ \\
\hline Oryza sativa L. & Arroz Crioulo. & Indiano * $^{*}$ \\
\hline Triticum aestivum L. & Trigo Antigo. & Ásia Central * \\
\hline Secale cereale L. & Centeio Antigo. & $\begin{array}{l}\text { Oriente Próximo e Ásia } \\
\text { Central * }\end{array}$ \\
\hline
\end{tabular}

Sorghum bicolor L. Caninha Vassoura, Vassoura. 


\section{SOLANACEAE}

Lycopersicum esculentum

Gaúcho, Coração de Boi,

Sul Americano *

Mill.

Cereja.

Capsicum sp..

Pimentinha, Pimenta.

Sul Americano *

ASTERACEAE

Helianthus annuus L. Girassol Gigante. América Central *

Lactuca canadensis L. $\quad$ Radite do Frade, Radite do China * Padre.

\begin{tabular}{lll}
\hline Lactuca sativa $\mathrm{L}$. & China *
\end{tabular}

Chichorium intybus L. $\quad$ Chicória, Radite.

LILLIACEAE

Allium cepa L. Cebola Roxa, Cebola Amarela. Ásia Central e China *

Allium sativum L. Alho-Cebola, Alho Gigante. Ásia Central *

\section{BRASSICACEAE}

Brassica oleracea L. $\quad$ Brócoli, Couve. Eurásia **

Brassica nigra L. $\quad$ Mostarda. $\quad$ Eurásia **

\section{APIACEAE}

\begin{tabular}{lll}
\hline $\begin{array}{l}\text { Petroselinum crispum } \\
\text { (Mill). Nym. }\end{array}$ & Salsa Crespa, Salsa. & Mediterrâneo ${ }^{* *}$ \\
\hline Daucus carota L. & Cenoura & Ásia Central *
\end{tabular}

\section{LINACEAE}

Linum usitatissimum L. Linhaça Dourada Oriente Próximo e Ásia

Central

AMARANTHACEAE

Amaranthus caudatus cf.L. Caruru Sul Americano*

MALVACEAE

Hibiscus sabdariffa L. Azedinha, Hibiscus. Indiano *

\section{POLYGONACEAE}

Fagopyrum esculentum Thigo Morisco Chine*

Gilib.

* Vavilov (1993);** Querol (1992);*** www.Kokopelli.org. 
Dentre as cucurbitáceas, o levantamento registrou principalmente uma grande diversidade de abóboras, morangas, melancias e melões 'crioulos', além de outras espécies não tão amplamente conhecidas da família (Tabela 2). As espécies demonstraram variedades de características peculiares quanto à morfologia dos frutos e em relação à forma de uso. A 'Abóbora Dez Mandamentos' ou 'Abóbora Estrela', é uma variedade tradicional de abóbora (Cucurbita pepo L.) mantida por agricultores da região do Planalto Médio do Rio Grande do Sul, na metade 'Norte' do estado (Figura 3). A variedade tem uso ornamental e alimentar, sendo, a partir dela, elaborados doces típicos. Sementes crioulas de duas variedades de melões (Cucumis melo L.) também foram identificadas no levantamento: os "melões de neve" - com outras denominações como 'bola de neve' ou 'pepino de neve' -, utilizados na forma de doce em sobremesas e os "melões doces", conhecidos como "gaúcho", "português" ou "doce”, para consumo in natura. Outra espécie da família identificada nos bancos de sementes dos "agricultoressementeiros” foi o 'maracujá' ou 'maracujá-melão' (Sicana odorifera (Vell.) Naudin). As variedades da espécie são mantidas devido aos seus usos diversos, como para elaborar sucos e perfumar guarda-roupas. Verificou-se a existência de variedades tradicionais de porongos bastante peculiares (Lagenaria siceraria (Mol) Standlh.), conhecidos como porongos de cuia, de metro - variedade de porongo chegando a atingir 1,5 metros de comprimento - e o porongo-de-chuchu, também conhecido como porongo-de-doce ou caxi, utilizado na alimentação. A partir desta variedade de porongo são fabricados doces e refogados.

As solanáceas apareceram no levantamento sendo representadas principalmente por variedades de tomates, de formas, tamanhos, resistência e cores muito variáveis. Variedades tradicionais de “Azedinha” ou "Vinagreira" (Hibiscus sabdariffa L.) e também de “caruru” (Amaranthus caudatus L. cf.) são mais alguns exemplos de espécies que ilustram a biodiversidade mantida nos bancos tradicionais dos agricultores-sementeiros do estado.

As gramíneas mostraram sua variabilidade mantida nos bancos de sementes amostrados através das diversas cores e formas de variedades tradicionais de milho, arroz, trigo, centeio, além de variedades da espécie Sorghum bicolor L., como a 'Vassoura' e a 'Cana-Vassoura'. As 
variedades conhecidas como 'Cana-Vassoura' são parecidas com outras variedades da espécie, mas estas apresentam além do 'pendão', utilizado para fazer vassouras de uso doméstico, um caule com característica alimentar, semelhante ao caule suculento da cana-de-açúcar, daí o nome. As variedades tradicionais de trigo comum (Triticum aestivum L.) são especialmente valorizadas pelos agricultores da região serrana em função da qualidade do grão, mas, principalmente, devido às características da palha. A partir da palha, que apresenta consistência e tamanho de hastes superior às variedades convencionais, os agricultores e agricultoras da Serra gaúcha ainda mantêm a tradição de origem italiana de confeccionar os próprios chapéus que usam no dia a dia da "lida" agrícola.

Figura 3: Variedade de Cucurbita pepo L., conhecida como 'Abóbora Dez Mandamentos', mantida na propriedade de Jorge Iaroseski, agricultor ecológico de Santo Antônio do Palma).

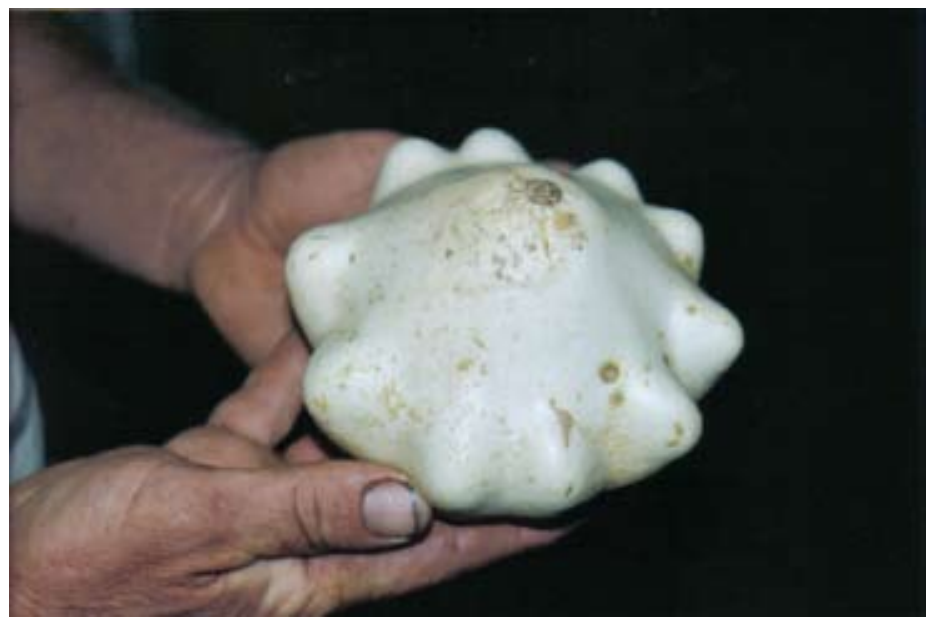

\subsection{Importância e dificuldades na manutenção das variedades tradicionais}

Através da sistematização dos dados levantados foi possível identificar as principais vantagens, de acordo com o olhar dos agricultores entrevistados, de ainda hoje manter as sementes de variedades antigas de plantas cultivadas nas propriedades. 
A entrevista semi-estruturada permitiu agrupar os depoimentos dos diferentes agricultores em sete categorias (Tabela 3). Durante as entrevistas realizadas também foi possível diagnosticar as principais dificuldades enfrentadas pelos agricultores na manutenção das sementes tradicionais, ao longo dos anos (Tabela 4).

Tabela 3: Vantagens atribuídas às sementes crioulas segundo os agricultores entrevistados.

\begin{tabular}{cc}
\hline Vantagem apontada & $\begin{array}{c}\text { Número de apontamentos } \\
\text { no total de entrevistados }\end{array}$ \\
Resistência ao clima, se adapta bem & 7 \\
Afetividade, valorização dos costumes & 7 \\
Baixo custo de produção & 6 \\
Sabor e qualidade & 6 \\
Boa aceitação no mercado & 4 \\
Manutenção da biodiversidade, práticas agroecológicas & 3 \\
Disponibilidade da semente no tempo certo & 3 \\
\hline
\end{tabular}

Tabela 4: Principais causas da perda de sementes tradicionais segundo os agricultores entrevistados

\begin{tabular}{cc} 
Principais causas da perda de sementes tradicionais & $\begin{array}{c}\text { Número de } \\
\text { apontamentos } \\
\text { nototal de entrevistados }\end{array}$ \\
Desinteresse das novas gerações, pouca mão de obra & 6 \\
Dificuldades em trocar/obter sementes & 6 \\
Fácil cruzamento com variedades híbridas e/ ou transgênicas & 4 \\
Falta de apoio/ incentivo/ mercados locais & 3 \\
\hline
\end{tabular}

\section{Discussão}

A diversidade de sementes de plantas tradicionais mantidas por agricultores nas propriedades amostradas revelou o enorme potencial de conservação existente nos bancos de sementes tradicionais do Rio Grande do Sul, principalmente quando um número significativo de regiões agroecológicas e diversidade de plantas cultivadas adaptadas a estes sistemas é somado à riqueza cultural envolvida na seleção de tais sementes. A amostragem realizada, de natureza não probabilística, 
serviu não como forma de representar o universo das sementes como um todo, mas como maneira de avaliar a diversidade de plantas tradicionais a partir de uma pequena amostra, bem como incentivar novos estudos que permitam futuramente um conhecimento mais aprofundado e possivelmente um mapeamento completo do estado.

Se voltarmos nosso olhar aos vários aspectos obtidos através da compilação das informações a respeito do perfil dos agricultoressementeiros amostrados no estudo, principalmente no que se refere às características sócioeconômicas, os dados nos remetem à discussão de que eles se caracterizam por serem agricultores de regime familiar de produção, com tradição agrícola. Esta última característica, presente em todas unidades amostrais, foi a grande responsável pela organização das propriedades amostradas na forma de agroecossistemas compostos de cultivos consorciados, com um grande número de espécies alimentícias envolvidas em suas composições. Tanto a opção por desenvolver uma agricultura de tradição, como as condições de isolamento ou marginalização - devido à impossibilidade financeira de se inserir ao modelo de agricultura vigente - foram fatores que tiveram papel importante na manutenção dos recursos e práticas tradicionais de muitos espaços agrícolas até o momento. No entanto, a "aspiração" pelo desenvolvimento de uma agricultura auto-suficiente, em diferentes épocas e sob muitas formas, configurou-se na principal responsável por ações inovadoras, que passaram a integrar o cotidiano e as discussões das famílias, repercutindo na reorganização de muitos espaços rurais gaúchos, em que as prioridades fossem tanto sociais, quanto ambientais e econômicas. Tais espaços foram, dessa forma, moldados principalmente por ações concretas reorientadas por um passado histórico recente de valorização dos recursos próprios e da autonomia familiar dos grupos, delineados por reflexões e ações conjuntas das comunidades rurais e agentes locais. Ações que se configuraram não apenas como um modo de produção, mas como uma escolha de vida.

De acordo com Santos (2005), em quase todos os municípios brasileiros, pode-se encontrar espaços de discussão, seja na forma de conselhos ou fóruns, porém nem sempre eles funcionam democraticamente, tendo muitas vezes uma existência meramente formal, dificultando a reorganização espacial a partir das prioridades 
da sociedade. Espaços construídos socialmente, segundo o autor, necessitam de três premissas básicas principais: organização de um espaço verdadeiramente democrático; a construção das chamadas 'agendas comuns' - possibilitando acordos coletivos entre diversos atores -, e, ainda, o incremento das dinâmicas adotadas em tais espaços. Santos (2005) refere-se ainda a diversos fatores políticos que orientaram muitas das ações locais existentes em certos grupamentos rurais do estado:

"A reorganização social no Brasil nos mais diversos segmentos da sociedade, tanto das cidades quanto do meio rural, iniciada nos anos 70, intensificou-se ainda mais nos anos 80, impulsionada principalmente pelos novos rumos delineados pela conquista de uma constituição denominada" Constituição Cidadã", através de movimentos sociais que procuravam aglutinar demandas de segmentos historicamente excluídos (...)". "Os primeiros passos desse processo de redemocratização foram impulsionados, em última instância, por uma iniciativa pioneira da Federação de Órgãos para Assistência Social e Educação (Fase), em 1980, ligada à rede PTA (Projeto de Tecnologias Alternativas)" (Santos, 2005, p.36 e 30).

O processo de interlocução com as comunidades rurais, no entanto, deu-se de forma distinta em diferentes regiões do estado gaúcho, atingindo de forma desigual os diferentes atores sociais, envolvidos e articulados em contextos socioambientais diversos. Naquelas regiões em que houve a continuidade de trabalho e também a articulação com outras instituições locais, os grupos organizados levaram adiante os processos de democratização, evoluindo nas suas formas organizativas e muitas vezes conquistando grande parte das necessidades buscadas. Tal realidade mostrou-se evidenciada nos municípios de Ipê, Antônio Prado, Santo Antônio do Palma e Canguçu, especialmente, em que o trabalho articulado entre agricultores e parceiros locais vem acontecendo já há algumas décadas, podendo ainda ser observada nestas regiões a consolidação das principais estratégias de abrangência regional diagnosticadas no levantamento.

Uma discussão recente, na tentativa de conservar os recursos das plantas cultivadas e possibilitar a sua disponibilidade a um maior número de agricultores quanto ao uso das sementes do sistema 
informal, se refere à necessidade ou não de seu registro no sistema nacional de proteção de cultivares (SNPC). Para alguns, a providência serviria como uma forma de equiparação das sementes informais ao status das sementes formais, onde ambas seguiriam as mesmas regras e também receberiam benefícios parecidos. Pautados na idéia de que se trata de uma questão mais complexa, há os que acreditam que, como já vem acontecendo em muitos países, o sistema informal pode ser fortalecido a partir de iniciativas de apoio institucional e governamental baseadas em uma lógica mais abrangente, que leve em consideração outros aspectos além do mercadológico, favorecendo de alguma forma quem realizar práticas de conservação destes recursos. Tais incentivos estariam focados na contribuição ambiental, social e econômica trazidas pelo uso das variedades tradicionais de plantas cultivadas ao ambiente e à sociedade como um todo.

A diversidade de variedades crioulas e os conhecimentos a respeito do manejo de tais variedades, identificados através da amostragem, nos dão apenas uma idéia do universo a ser pesquisado, apontando para a necessidade de realização de mais trabalhos de pesquisa, coleta e identificação que sejam, acima de tudo, promotores tanto das práticas de manejo associadas às variedades quanto da ampliação de seu uso por um número crescente de agricultores. No entanto, para que haja a multiplicação e valorização das variedades locais e do manejo associado, além do trabalho da pesquisa, torna-se necessário que esta promoção seja feita pela sociedade como um todo, através de suas escolhas. E para que as escolhas caminhem nesta direção, qualquer trabalho em torno da questão deve estar pautado na manutenção e resgate dos valores desta sociedade, ou seja, nos valores das gerações de hoje, mas principalmente, nos valores das gerações futuras.

Com relação às causas da perda de sementes tradicionais, um fator, indicado pela maior parte dos agricultores, pode servir como ilustração. O desinteresse das novas gerações, apontado por 46\% dos entrevistados, se configura hoje num grande desafio à manutenção da agricultura familiar e de todos os recursos manejados e mantidos por ela, e isto inclui as sementes tradicionais, principalmente devido ao fato da troca entre familiares ser a principal forma de intercâmbio de sementes. De acordo com Schio et al., (2005), existe a constatação de 
que os jovens buscam alternativas para a permanência no meio rural. No entanto, a desvalorização, tanto financeira quanto do seu papel como futuro agricultor, faz voltar a atenção da maior parte dos jovens a outras alternativas econômicas. As atribuições das atividades agrícolas, antes divididas entre um grande número de integrantes da família, hoje não encontram mais espaço e, muitas das práticas que há décadas ou séculos vinham sendo realizadas, vão gradativamente caindo no esquecimento.

As estratégias encontradas nos diferentes locais de amostragem evidenciaram a criatividade e também a forte presença da articulação local entre os diferentes atores sociais, mostrando que a integração pode resultar em construções coletivas muito frutíferas. As dificuldades elencadas pelos agricultores e agricultoras entrevistados diferiram pouco em cada uma das realidades, ficando claro que são necessárias políticas públicas e parcerias institucionais, nos diversos âmbitos, a fim de amenizar as dificuldades elencadas para a manutenção e promoção do uso das sementes tradicionais.

São muitas as instituições que hoje mantêm algum tipo de relação com as comunidades rurais tradicionais, sejam ONGs, órgãos de pesquisa ou de extensão, como verificado no próprio levantamento realizado. $\mathrm{O}$ fato de haver, segundo $69 \%$ dos entrevistados, algum tipo de relação com instituições de extensão e apenas $15 \%$ deles se referirem a elas como promotoras da conservação de variedades tradicionais, aponta claramente a necessidade de uma profunda reorientação da ação de tais instituições, no sentido de contribuir efetivamente no desenvolvimento econômico, social e ambiental desses espaços rurais.

Segundo Gliessman (2000), a conservação realizada na propriedade agrícola envolve seleção e mudança genética contínua, em vez de preservação estática. Esta forma de conservação requer, ainda, que as unidades de produção agrícola e os produtores, sejam os repositórios tanto da informação genética como do conhecimento cultural de como os cultivos são manejados. Esta co-evolução, ao tornar as plantas cultivadas adaptadas aos locais de cultivo, faz com que sejam facilmente manejadas pelos agricultores, otimizando a fonte de recursos e diminuindo a vulnerabilidade destes frente a situações ambientais adversas. Os agricultores e agricultoras, ao atribuírem às plantas crioulas as características de "maior resistência” ou "menor exigência", 
se referem a um aspecto muito relevante: a garantia da segurança alimentar das famílias através do estabelecimento dos cultivos na época e da forma que julgarem mais adequadas, com poucos recursos (muitas vezes oriundos unicamente da propriedade) quanto aos insumos.

Tal característica pode receber a denominação de adaptação. Carvalho (2003) descreve que desde o período colonial, a adaptação e o melhoramento genético do "germoplasma” exótico às distintas condições de clima e solo eram realizadas pelos colonos, que se utilizavam também de parte dos conhecimentos acumulados pelas populações indígenas sobre as espécies silvestres e cultivadas de origem principalmente centro-sul americanas. Há referências sobre a existência de variedades de milho indígena que ainda hoje têm significado alimentar e religioso em comunidades Guarani do estado (Ikuta, 2002; Delwing et al., 2003). No entanto, tanto as plantas cultivadas originárias de centros de origem americanos como aquelas de centros de origem exóticos são fruto da coevolução entre os vários fatores ambientais em que se desenvolveram e também entre essas plantas e seus "melhoristas", já que muitas das plantas introduzidas têm histórico de até 400 anos de domesticação em nosso continente.

A falta de valorização, tanto do trabalho de manutenção quanto do produto desse trabalho tem, assim, contribuído significativamente para a perda de variedades tradicionais pertencentes a muitas famílias de plantas domesticadas. Esta realidade acelera ainda mais o passo quando aquelas propriedades que ainda mantêm um grupo coeso, envolvido nas atividades da propriedade, adotam cultivos em maior escala, subutilizando e perdendo, com o passar do tempo, recursos de grande valor biológico e cultural.

A multifuncionalidade, de acordo com Carneiro \& Maluf (2003), é um conceito que rompe com o enfoque setorial e amplia o campo das funções sociais atribuídas à agricultura, que deixa de ser entendida apenas como produtora de bens agrícolas. Ela se torna responsável pela conservação dos recursos naturais (água, solos, biodiversidade), do patrimônio natural (paisagens) e pela qualidade dos alimentos. Alier (1998) afirma que o ecologismo político internacional se apóia na crítica ecológica à agricultura moderna, que em resumo argumenta que a maior produtividade deste tipo de agricultura, pobre em biodiversidade e intensa em energia de 
combustíveis fósseis, oculta custos ecológicos que não são medidos pelos preços do mercado. A compreensão a respeito da importância da manutenção e multiplicação desses espaços rurais, que somam eqüidade social com responsabilidade ambiental, pode ser um passo decisivo em direção a uma nova concepção de agricultura e também de conservação, que tenha como produto final um ambiente mais equilibrado, contabilizando os mais variados aspectos além do econômico.

\section{Conclusões}

Existe grande diversidade de sementes tradicionais de plantas cultivadas mantidas nos bancos de sementes de muitos agricultores do Rio Grande do Sul.

As principais causas da preferência dos agricultores-sementeiros mostra que, para muitos deles, as variedades tradicionais têm um papel econômico e afetivo muito importantes na dinâmica de vida e também na lógica de funcionamento das propriedades. A 'resistência ao clima' e a 'adaptação', algumas das principais vantagens da utilização de sementes tradicionais, segundo os entrevistados, são características que auxiliam no manejo agrícola, uma vez que fazem com que não se necessite de um aporte muito grande de insumos que, em sua maioria, são oriundos da propriedade. Outras características como o 'melhor sabor' e a 'melhor qualidade' são, segundo a maior parte dos entrevistados, motivo da utilização de tais variedades até os dias de hoje, estando fortemente relacionadas à afetividade e valorização dos costumes, sem as quais, muitas vezes, a própria razão de existir de muitas comunidades desaparece e, juntamente com ela, a diversidade biológica mantida.

As principais dificuldades enfrentadas pelos agricultores podem ser descritas por três apontamentos mais relevantes: a dificuldade em trocar e obter sementes, o desinteresse das novas gerações e a fragilidade dos cultivos devido a cruzamentos não controlados.

Em cada uma das regiões, a articulação entre as organizações dos agricultores e as diferentes instituições (ONGs, movimentos sociais e instituições públicas) foi responsável por passos decisivos na construção de alternativas à conservação da agrobiodiversidade local. 


\section{Agradecimentos}

Os autores agradecem os muitos colaboradores deste trabalho, que vão desde os representantes das diferentes instituições entrevistadas, pesquisadores e colaboradoras até os agricultores, os protagonistas de fato, que na perseverança avançam em busca de uma agricultura que possibilite produzir, conservar e viver de forma digna.

\section{Referências Bibliográficas}

ALIER, M. J. Da Economia Ecológica ao Ecologismo Popular. Blumenau: Ed. da FURB, 1998. 402p.

ALMEIDA, A. CORDEIRO, P. Semente da paixão: estratégia comunitária de conservação de variedades locais no semi-árido. Rio de Janeiro: ASPTA 2002. 72p.

BERMEJO, H.J.E; LEON, J. Cultivos Marginados: otra perspectiva de 1492. Jardin Botânico de Córdoba (España), Roma : FAO, 1992. 339p. (Coleción FAO: Producción y proteción vegetal, 26).

BERNARD, H.R. Research methods in cultural anthropology. Newbury Park: Sage Publications, 1988. 520 p.

BRUSH, S.B. (Ed.) Genes in the field: on-farm conservation of crop diversity. U.S.A: Lewis Publishers, 2000. 287.

CARVALHO, H. (Org.) Sementes: patrimônio do povo a serviço da humanidade. São Paulo: Expressão Popular, 2003. 352p.

CARNEIRO, M. J. MALUF, R. S. (Orgs.) Para além da produção: multifuncionalidade e agricultura familiar. Rio de Janeiro: MAUAD, 2003. $230 \mathrm{p}$.

DELWING, A.B. et al. Análise das relações etnoambientais de uma comunidade indígena Mbyá Guarani na busca de evidências e formas de manutenção de seus conhecimentos e técnicas tradicionais. In: CONGRESSO BRASILEIRO DE ECONOMIA E SOCIOLOGIA RURAL, 41., 2003, Juiz de Fora: Anais ... Juiz de Fora: SOBER, 2003. 1 CD-ROM. 
DOMINGUEZ, O. C. E. et al. Sistema informal de sementes: causas, conseqüências e alternativas. Pelotas: Editora Universitária/UFPel, 2000. 207p.

DUTRA, O. Importação de sementes de olerícolas no Rio Grande do Sul. Porto Alegre: Ministério da Agricultura, Pecuária e Abastecimento, Setor de Importação de Sementes, 6,7 e 8 de junho, 2005. Informações verbais obtidas em entrevista e levantamento quantitativo de sementes de olerícolas importadas no estado do Rio Grande do Sul realizados por Andréa Becker Delwing.

EVANS, L.T. Crop, evolution, adaptation and yield. Cambridge: Cambridge University Press. 1996. 500 p.

GAIFAMI, A; CORDEIRO, A. Cultivando a diversidade: recursos genéticos e segurança alimentar local. Rio de Janeiro: ASPTA, 1994. $205 \mathrm{p}$.

GLIESSMAN, S.R. Agroecologia: processos ecológicos em agricultura sustentável. Porto Alegre: Editora Universidade/UFRGS,2000.653 p.

HEISER, C. B. Sementes para a civilização: a história da alimentação humana. São Paulo: Ed. Nacional, Ed da Universidade de São Paulo, 1977. $253 \mathrm{p}$.

IKUTA, A.R.Y. Práticas fitotécnicas de uma comunidade indígena mbyá guarani, Varzinha, Rio Grande do Sul: da roça ao artesanato. 2002, 307 f. Tese (Doutorado) - Programa de Pós Graduação em Fitotecnia, Faculdade de Agronomia, Universidade Federal do Rio Grande do Sul, Porto Alegre, 2002.

LOUWAARS, N. P. Seeds supply systems in the tropics. Wageningen: IAC/University of Wageningen, 1994. $161 \mathrm{p}$.

MAZOYER, M.; ROUDART, L. História das agriculturas do mundo: do neolítico à crise contemporânea. Lisboa: Instituto Piaget. 520 p.

MOONEY, P. R. O escândalo das sementes: o domínio da produção de alimentos. São Paulo: Nobel, 1987. 146 p.

ORNELLAS, L. H. A alimentação através dos tempos. Florianópolis: Ed da UFSC, 2003. 307 p. 
PESSANHA, L. Sementes: biodiversidade, biotecnologias e propriedade intelectual. Rio de Janeiro: AS-PTA. Flacso, 1995. 49 p.

PINHEIRO, S.; NASR, N. Y.; LUZ, D. A agricultura ecológica e a máfia dos agrotóxicos no Brasil. Porto Alegre: Edição dos Autores, 2000. 356 p.

PINHEIRO, S. “Agronegocio o servidumbre?”. Farroupilha, Rede ECOVIDA, 2005. Palestra e discussão com agricultores integrantes da rede ecovida de certificação participativa de produtos orgânicos. Discussão posterior (contato pessoal) sobre as sementes tradicionais ou crioulas no Brasil e Rio Grande do Sul.

QUEROL, D. Recursos genéticos, nosso tesouro esquecido: abordagem técnica e sócio econômica. Trad. Joselita Wasniewski - Rio de Janeiro: AS-PTA, 1993. 206 p.

RAVEN, P. et al. Biologia vegetal. Rio de Janeiro: Guanabara Koogan S.A. 1996.728 p.

RUBERT, R.A. Comunidades negras rurais do RS: um levantamento socioantropológico preliminar. Porto Alegre: RS RURAL, IICA, 2005. 173 p.

SANTOS, A.D. (Org.) Metodologias participativas: caminhos para o fortalecimento de espaços públicos socioambientais. IEB: Instituto Internacional de Educação do Brasil. São Paulo: Petrópolis, 2005. 180 p.

SCHIO, P.J. B et al. Juventude e agricultura ecológica no Rio Grande do Sul. Agriculturas: experiências em Agroecologia, Rio de Janeiro, v. 2, p 6-9, 2005.

SCHNEIDER, S.; WAQUIL, P. D. Caracterização sócio-econômica dos municípios gaúchos e desigualdades regionais. Revista de Economia e Sociologia Rural, Brasília, v. 39, p 117-142, 2001.

VERDUM, R.; BASSO, L. A.; SUERTEGARAY, D. M. A. Rio Grande do Sul: paisagens e territórios em transformação. Porto Alegre: Editora da UFRGS, 2004. 